\title{
CONTRIBUIÇÕES SINDICAIS E A LIBERDADE SINDICAL DO TRABALHADOR CELETISTA
}

\section{UNION CONTRIBUTIONS AND FREEDOM OF ASSOCIATION OF CLT WORKER}

Rubens Patruni Filho ${ }^{1}$

\section{RESUMO}

Este trabalho tem por objetivo apresentar o verdadeiro significado de liberdade sindical prevista no artigo $8^{\circ}$ da constituição federal. A liberdade sindical garantida ao trabalhador é muitas vezes mitigada de modo a ignorar sua vontade de filiação à entidade sindical. Os sindicatos, por meio de convenções coletivas de trabalho ou acordos coletivos, vêm impondo a todos os trabalhadores, filiados ou não, a responsabilidade de arcar com os custos do sistema confederativo e também os demais gastos dos sindicatos, tais como atividades assistenciais e de negociação coletiva. No caso dos trabalhadores regidos pela consolidação das leis trabalhistas (CLT) as contribuições são descontadas diretamente dos salários, mesmo contrariando a vontade do trabalhador.

Palavras-chave: Liberdade, Trabalhador, Sindicato, Contribuições, Filiação

\begin{abstract}
This work aims to present the true meaning of freedom of association under Article 8 of the federal constitution. The freedom guaranteed to the worker is often mitigated to ignore their willingness to membership in a labor union. The unions, through collective labor agreements or collective agreements, are imposing to all employees, affiliated or not, the responsibility to bear the costs of the confederation system and also other expenses of unions such as welfare activities and trading conference. In the case of workers covered by the consolidation of labor laws (CLT) contributions are deducted directly from wages, even against the wishes of the employee.
\end{abstract}

Keywords: Freedom, Worker, Union, Contributions, Membership

\footnotetext{
${ }^{1}$ Pós Graduado em Direito do Trabalho, Processo do Trabalho e Previdência pelo Instituto Nacional de Ensino e Pesquisa - Faculdade INESP, São Paulo, (Brasil). E-mail: rubenspatruni@gmail.com
} 


\section{INTRODUÇÃO}

O trabalho é fundamental para o crescimento e desenvolvimento de uma sociedade. As relações de trabalho que ocorrem entre empregados e empregadores são vigiadas pelo Estado e por organizações sindicais, de modo a buscar um equilíbrio entre empresas e trabalhadores.

O equilíbrio é necessário uma vez que os trabalhadores, devido ao poder do capital imposto pelas empresas, são o elo fraco nessa relação. Para isso há um conjunto de normas jurídicas, baseadas em princípios norteadores do direito do trabalho com o fim de buscar o balanceamento nas relações trabalhistas.

O princípio protetor ocorre desde a elaboração das normas jurídicas já com o entendimento da hipossuficiência do trabalhador e passa por diversos outros conceitos de proteção como a aplicação da norma mais favorável, da condição mais benéfica, da irrenunciabilidade dos direitos trabalhistas, dentre outros.

O desequilíbrio na relação trabalhista entre patrões e empregados, quase sempre impede que o trabalhador, sozinho, busque a aplicação dos seus direitos. Para atender essa necessidade entram em cena os sindicatos, que são agentes representativos, de uma coletividade de trabalhadores em diversas esferas. Os sindicatos representam uma categoria de trabalhadores visando a defesa dos direitos dessas pessoas, objetivo esse determinado pela carta magna vigente em nosso país.

Ocorre que, para fazer a representação dos trabalhadores, os sindicatos obreiros vêm criando e impondo contribuições com a justificativa de arcar com os custos da sua atuação, independentemente da filiação desses trabalhadores junto aos sindicatos. Para isso, utilizamse dos acordos e convenções coletivas de trabalho. Esses instrumentos criam normas e vinculam às partes no cumprimento daquilo que foi acordado, independentemente da legalidade e da observância das leis e princípios trabalhistas.

É aí que surgem alguns questionamentos a respeito da função dos sindicatos e da liberdade dos trabalhadores para adesão aos mesmos. Há a garantia constitucional da liberdade sindical embutida no caput do artigo $8^{\circ}$ da Constituição Federal. O alcance dessa garantia, de forma geral, está sendo mitigado pelos sindicatos dos trabalhadores, com a justificativa da necessidade do aparelhamento sindical. A cobrança de contribuições, de maneira forçada, de trabalhadores não filiados é uma forma de ignorar a liberdade sindical e retirar desses trabalhadores a sua liberdade de escolha de filiação.

Essa mitigação contraria as leis trabalhistas, sobretudo os princípios do direito do trabalho que garantem aos trabalhadores, de forma primária, o exercício do trabalho regido dentro de parâmetros mínimos de dignidade das condições humanas provenientes das relações do trabalho. 


\section{SINDICATO LABORAL}

Sindicato é uma associação de empregadores e trabalhadores, podendo esse último, ser formado por trabalhadores celetistas, autônomos, profissionais liberais, dentre outras classes e grupos.

Para Maurício Godinho Delgado, os sindicatos são:

... entidades associativas permanentes, que representam trabalhadores vinculados por laços profissionais e laborativos comuns, visando tratar de problemas coletivos das respectivas bases representadas, defendendo seus interesses trabalhistas e conexos, com o objetivo de lhes alcançar melhores condições de labor e vida. ${ }^{2}$

São pessoas jurídicas de direito privado, ou seja, possuem natureza privada que busca defender os direitos trabalhistas de uma classe de trabalhadores.

A associação profissional ou sindical é livre, conforme descrito no caput do artigo $8^{\circ}$ da Constituição Federal de 1988. Além disso, a criação dos sindicatos não deve sofrer restrição, devendo o poder público apenas registrar a sua criação. O art. $8^{\circ}$, I, da Constituição garante o direito de formação de sindicatos sem que haja uma autorização do Estado para sua fundação.

Art. $8^{\circ}$ - É livre a associação profissional ou sindical, observado o seguinte:

I - a lei não poderá exigir autorização do Estado para a fundação de sindicato, ressalvado o registro no órgão competente, vedadas ao Poder Público a interferência e a intervenção na organização sindical;

Esse dispositivo garante ao sindicato condições para atingir seu objetivo sem que haja a interferência e a intervenção do Estado, sendo apenas necessário o registro em órgão competente.

\subsection{A FUNÇÃO DO SINDICATO}

O objetivo central dos sindicatos está descrito no inciso III do artigo $8^{\circ}$ da Constituição Federal de 1988.

Art. $8^{\circ}$ - É livre a associação profissional ou sindical, observado o seguinte:

( ...)

III - ao sindicato cabe a defesa dos direitos e interesses coletivos ou individuais da categoria, inclusive em questões judiciais ou administrativas;

\footnotetext{
${ }^{2}$ DELGADO, Maurício Godinho. Curso de direito do trabalho. 9. ed. São Paulo: LTr, 2010.
} 
Assim, o sindicato deve atuar em prol dos trabalhadores que representa, celebrando contratos coletivos de trabalho, de modo que os trabalhadores tenham assegurados seus direitos constitucionais e trabalhistas, em todas as esferas, inclusive judicial e administrativa.

Além disso, o art. 514 da CLT norteia a atuação do sindicato, atribuindo deveres mandamentais, de modo a atender a classe trabalhadora.

Os sindicatos devem colaborar com os poderes públicos no desenvolvimento da solidariedade social, manter serviços de assistência judiciária para os associados e promover a conciliação nos dissídios de trabalho. Sempre que possível deve manter um assistente social para promover a cooperação operacional na empresa e a integração profissional. Também devem promover a fundação de cooperativas de consumo e de crédito e disponibilizar escolas de alfabetização e profissionais.

Todas essas atribuições previstas em lei demandam um custeio de forma a concretizar a atuação sindical e o atendimento ao trabalhador, com qualidade e efetividade.

Para isso, a entidade recebe parte do imposto sindical, previsto no art. 580 da CLT, além de ter a prerrogativa de impor contribuições aos trabalhadores cuja atividade está organizada em categorias econômicas.

\subsection{FONTES DE CUSTEIO DOS SINDICATOS}

O custeio das entidades sindicais é condição para que seja possível a atuação e busca dos objetivos centrais dos sindicatos para atendimentos dos trabalhadores. Tanto a Constituição Federal, quanto a Consolidação das Leis do Trabalho, preveem a instituição de contribuições para o custeio sindical.

O juiz Valentin Carrion, falecido em 2000, classificou as contribuições sindicais em quatro espécies ${ }^{3}$.

a) Contribuição legal - é a chamada contribuição sindical que é geral para todos os trabalhadores, fixada por lei;

b) Contribuição assistencial - da categoria ou coletiva;

c) Contribuição de associado ou voluntária - mensalidade sindical;

d) Contribuição confederativa.

De maneira geral a literatura existente faz a mesma classificação com alguma diferença na nomenclatura. Vamos entender cada uma dessas contribuições. 


\subsubsection{CONTRIBUIÇÃO SINDICAL}

A contribuição sindical está prevista no artigo $8^{\circ}$ da CF e sua fixação e forma de arrecadação está descrita nos artigos 578 a 591 da CLT.

Art. $8^{\circ}$ - É livre a associação profissional ou sindical, observado o seguinte:

(...)

IV - a assembleia geral fixará a contribuição que, em se tratando de categoria profissional, será descontada em folha, para custeio do sistema confederativo da representação sindical respectiva, independentemente da contribuição prevista em lei; (grifo nosso).

O artigo acima autoriza duas formas de arrecadação. A primeira é a contribuição que deverá ser fixada pela assembleia geral e que trataremos em seguida. A outra contribuição deverá ser criada por lei, o que lhe atribui natureza tributária, conforme preconiza o princípio da legalidade tributária presente o artigo 150, I da Constituição Federal.

A contribuição prevista em lei citada no inciso IV do artigo $8^{\circ}$ é a contribuição sindical descrita no capítulo III da CLT, mas especificamente no art. 580. Essa contribuição deverá ser descontada pelos empregadores no mês de março de cada ano e corresponderá a um dia de trabalho para os empregados, qualquer que seja a sua remuneração, e repassada ao sindicato correspondente.

É essa a principal forma de custeio das entidades sindicais para que possam desenvolver a atividade sindical, construindo sedes, oferecendo serviços aos associados, realizando eventos sociais e festivos, e demais objetivos elencados no inciso II do art. 592 da CLT.

A contribuição prevista na CLT é compulsória, ou seja, todo trabalhador, sindicalizado ou não, deve contribuir com a entidade, uma vez que, independentemente de ser filiado, também terá benefícios da atuação sindical.

\subsubsection{CONTRIBUIÇÃO ASSISTENCIAL}

Temos também a previsão no art. 513 da norma trabalhista que dá ao sindicato a prerrogativa de impor contribuições a todos que participam de categorias econômicas ou profissionais. Trata-se da contribuição assistencial e há diversas opiniões quanto ao objetivo desse reforço financeiro. Talvez seja por isso que diversas entidades sindicais nomeiam a referida contribuição de formas diversas, como contribuição negocial, reversão salarial, de revigoramento ou simplesmente assistencial.

\footnotetext{
${ }^{3}$ CARRION, Valentin, 1931-2000. Comentários à consolidação das leis do trabalho. 35. ed. atual. Por Eduardo Carrion. São Paulo: Saraiva, 2010, p. 502.
} 
Nas palavras de Maurício Godinho Delgado, "Recebe também outras denominações, na prática trabalhista, como taxa de reforço sindical, contribuição de reforço sindical, etc.". 4

Num artigo escrito por Tamira Maira Fioravante e Luiz Fernando Alouche, do escritório Almeida Advogados, os autores citam que a contribuição assistencial é cobrada em virtude dos resultados obtidos durante uma negociação salarial.

A Contribuição Assistencial, por definição, visa retribuir o Sindicato pelo resultado obtido em eventual negociação coletiva de trabalho da qual participou como representante da sua respectiva categoria. ${ }^{5}$

Um exemplo de contribuição assistencial com a nomenclatura de negocial está na Convenção Coletiva de Trabalho ${ }^{6}$ (CCT) 2014/2015 firmado entre o sindicato da indústria da construção civil do oeste do Paraná e sindicatos obreiros de diversos municípios, cujo teor foi depositado no Ministério do Trabalho e Emprego sob o $\mathrm{n}^{\circ}$ PR003097/2014. Vejamos a cláusula 40 (quarenta) da norma coletiva:

\section{Contribuições Sindicais}

\section{CLÁUSULA QUADRAGÉSIMA - CONTRIBUIÇÃO NEGOCIAL}

Para assegurar a unicidade jurídica do presente instrumento, retribuir o empenho e trabalho sindical para a realização do mesmo, manter as atividades sindicais e cumprir determinação da Assembleia Geral, as empresas descontarão de seus empregados os seguintes valores, a título de CONTRIBUIÇÃO NEGOCIAL, de conformidade com o artigo 462, 545 e letra e do artigo 513 da CLT. (grifo nosso)

\section{(...)}

Não há qualquer tipo de distribuição dessa contribuição, ou seja, 100\% (cem por cento) do montante arrecadado vão diretamente para o sindicato que a estipulou. Também não há natureza tributária nesse tipo de contribuição, uma vez que não foi estipulada por lei, e sim por norma coletiva de trabalho (ACT ou CCT).

\subsubsection{MENSALIDADE SINDICAL}

A mensalidade sindical é outra forma de custeio e está baseada no art. 548 -b da CLT, e pode ser criada na forma estabelecida nos estatutos ou pelas assembleias gerais.

\footnotetext{
${ }^{4}$ DELGADO, Maurício Godinho. Curso de direito do trabalho. 9. ed. São Paulo: LTr, 2010.

${ }^{5}$ FIORAVANTE, Tamira Maira e ALOUCHE, Luiz Fernando. Fontes de custeio dos sindicatos no Brasil. Disponível em: < http://www.migalhas.com.br/dePeso/16,MI139029,91041Fontes+de+custeio+dos+sindicatos+no+Brasil>. Acesso em: 19 set. 2014.

${ }^{6}$ CONVENÇÃO Coletiva de Trabalho 2014/2015 dos trabalhadores da indústria da construção civil. Sistema de negociações coletivas de trabalho - MEDIADOR. Registrada em 25/07/2014. Disponível em: <http://www3.mte.gov.br/sistemas/mediador/ConsultarInstColetivo>. Acesso em: 4 set. 2014.
} 
Fica claro no caso dessa contribuição que a mesma é devida apenas aos associados, uma vez que está descrito de forma literal no art. 548. Da mesma forma que a contribuição confederativa prevista no inciso IV do art. $8^{\circ}$ da $\mathrm{CF}$, a criação da mensalidade sindical deve ser decidida em assembleia geral ou estar discriminada no estatuto da entidade sindical.

Em ambos os casos deve obedecer às formalidades impostas, seja pelo próprio estatuto ou por normativa legal no caso da criação do estatuto. O valor da mensalidade sindical e a forma de cobrança são de livre escolha da assembleia geral.

Usualmente constam nas convenções coletivas de trabalho e também nos acordos coletivos, a discriminação desses valores e os prazos para recolhimento.

Vejamos essa previsão na cláusula 49 (quarenta e nove) da Convenção Coletiva de Trabalho $^{7}$ (CCT) 2013/2015 firmado entre o sindicato dos professores das instituições privadas de ensino superior da cidade de Cascavel e o sindicato dos estabelecimentos particulares de ensino do estado do Paraná (registro n PR001155/2015).

\title{
CLÁUSULA QUADRAGÉSIMA NONA - $\quad$ DAS MENSALIDADES E DESCONTOS AO SINDICATO
}

\begin{abstract}
Os estabelecimentos de ensino superior não obstarão a sindicalização de seus empregados docentes, obrigando-se a descontar em folha de pagamento, desde que por eles devidamente autorizados, a mensalidade devida e outros descontos a seu favor decorrentes de convênios, efetuando o recolhimento à entidade Sindical até o dia 10 (dez) do mês subsequente ao que deu origem ao desconto, sob pena de, não o fazendo neste prazo, incorrem na atualização monetária pelos índices oficiais de mercado. O SINPRO fornecerá os impressos próprios para este recolhimento em época oportuna e caso na o faça não haverá incidência de atualização monetária nos valores a serem recolhidos.
\end{abstract}

Toda a arrecadação da mensalidade é destinada ao sindicato, não havendo repartição do montante arrecadado.

\subsubsection{CONTRIBUIÇÃO CONFEDERATIVA}

Da mesma forma que a contribuição sindical, a contribuição confederativa está prevista no artigo $8^{\circ}$, inciso IV da constituição federal de 1988:

Art. $8^{\circ}$ - É livre a associação profissional ou sindical, observado o seguinte:

(...)

IV - a assembleia geral fixará a contribuição que, em se tratando de categoria profissional, será descontada em folha, para custeio do sistema confederativo da representação sindical respectiva, independentemente da contribuição prevista em lei; (grifo nosso). 
A contribuição confederativa deve ser criada obedecendo às formalidades previstas. O inciso IV do art. $8^{\circ}$ dita que a criação deve ser em assembleia geral. Desta forma, não tem o presidente do sindicato ou qualquer uma das diretorias a competência para a criação da contribuição confederativa, pois cabe à assembleia fazê-lo.

Trata-se de contribuição privada, sem natureza de tributo, fixada para custear o sistema confederativo sindical. O sistema confederativo é composto pelos entes que representam uma determinada categoria profissional, quais sejam os sindicatos, as federações e as confederações. Nesse caso, os sindicatos são entidades de $1^{\circ}$ grau, seguidos das federações $\left(2^{\circ}\right.$ grau) e confederações $\left(3^{\circ}\right.$ grau). É importante destacar que as centrais sindicais são regidas por lei própria e não há consenso sobre sua inclusão no sistema confederativo proposto pela $\mathrm{CF}-88$.

\section{LIBERDADE SINDICAL}

Muito embora o Estado brasileiro não tenha ratificado a Convenção n ${ }^{\circ} 87$ da OIT Organização Internacional do Trabalho, a liberdade sindical está inserida na Constituição Federal de 1988, em seu artigo $8^{\circ}$, tanto a liberdade de fundação dos sindicatos (inciso I), quanto de filiação aos mesmos (inciso V):

Importante ressaltar que a liberdade sindical inserida na Convenção $\mathrm{n}^{\circ} 87 \mathrm{da}$ OIT, remonta do ano de 1948. O artigo $2^{\circ}$ da convenção internacional preconizou, quarenta anos antes da CF 88, o seguinte:

Art. 2 - Os trabalhadores e os empregadores, sem distinção de qualquer espécie, terão direito de constituir, sem autorização prévia, organizações de sua escolha, bem como o direito de se filiar a essas organizações, sob a única condição de se conformar com os estatutos das mesmas.

A livre associação prevista no artigo $8^{\circ}$ da CF abrange tanto a liberdade coletiva, quanto a liberdade individual. A liberdade coletiva é a garantia de não interferência do Estado na decisão de uma coletividade de trabalhadores e empregadores de fundar um sindicato que represente seus interesses. Segundo Alberto Emiliano de Oliveira Neto, procurador do trabalho, "a ideia de independência representada pela garantia de autonomia dos órgãos sindicais frente ao Poder Público e toda a intervenção que tenda a limitar o poder dos sindicatos. $" .8$

Art. $8^{\circ}$ É livre a associação profissional ou sindical, observado o seguinte:

I - a lei não poderá exigir autorização do Estado para a fundação de sindicato, ressalvado o registro no órgão competente, vedadas ao Poder Público a interferência e a intervenção na organização sindical;

(...)

V - ninguém será obrigado a filiar-se ou a manter-se filiado a sindicato; 


\section{(...)}

A liberdade sindical individual é condição para que trabalhadores e empregadores exerçam seu direito de escolha sindical, optando ou não pela sua filiação junto a um determinado sindicato. Segundo o inciso $\mathrm{V}$, do artigo $8^{\circ}$ da $\mathrm{CF}$, -ninguém será obrigado a filiar-se ou manter-se filiado a sindicato.

Desta forma, percebemos que essa liberdade sindical pode ser positiva ou negativa, ou seja, o trabalhador pode optar em querer ou não querer participar do sindicato. A escolha é exclusivamente do trabalhador, é um direito garantido pela constituição e não deve ser mitigado, senão pela vontade popular, através de uma nova constituição.

É um princípio fundamental reconhecido dentro do direito internacional do trabalho, expresso na Convenção $n^{\circ} 87$ da OIT e também no Tratado de Versalhes ${ }^{9}$, que deu origem à OIT, cuja constituição corresponde à Parte XIII do tratado. Por ser um princípio, a liberdade sindical dá pose fundamental de maneira a contribuir para a preservação da democracia.

O artigo 23 da Declaração dos Direitos Humanos ${ }^{10}$ também destaca a liberdade sindical o que reforça o caráter de princípio fundamental uma vez que se trata de um documento de proteção universal dos direitos humanos.

\section{(..)}

\section{Artigo 23.}

1. Toda a pessoa tem direito ao trabalho, à livre escolha do trabalho, a condições equitativas e satisfatórias de trabalho e à proteção contra o desemprego.

2. Todos têm direito, sem discriminação alguma, a salário igual por trabalho igual.

3. Quem trabalha tem direito a uma remuneração equitativa e satisfatória, que lhe permita e à sua família uma existência conforme com a dignidade humana, e completada, se possível, por todos os outros meios de proteção social.

4. Toda a pessoa tem o direito de fundar com outras pessoas sindicatos e de se filiar em sindicatos para defesa dos seus interesses.

(...)

(grifo nosso).

\footnotetext{
${ }^{7}$ CONVENÇÃO Coletiva de Trabalho 2014/2015 dos professores das instituições privadas de ensino superior de Cascavel. Sistema de negociações coletivas de trabalho - MEDIADOR. Registrada em $31 / 03 / 2014$. Disponível em:

<http://www3.mte.gov.br/sistemas/mediador/ConsultarInstColetivo〉. Acesso em: 5 set. 2014.
} 
A interpretação constitucional da liberdade sindical deve estar vinculada ao entendimento de principio fundamental, desta forma temos que essa liberdade está diretamente ligada a outros princípios, como a dignidade da pessoa humana e do direito ao trabalho.

Desta feita, a filiação é ato facultativo do trabalhador uma vez que goza da liberdade sindical prevista na CF-88. Essa liberdade é irrestrita e garante a todos os trabalhadores e empregadores criar organizações a sua escolha, além de optar pela adesão.

Essa liberdade engloba o direito à liberdade individual e coletiva e também às proteções do trabalho, como a discriminação e o assédio, defendidos pelas entidades representativas.

\subsection{FILIAÇÃ̃O}

Como já vimos, a filiação de um trabalhador a um sindicato é ato volitivo. Uma vez que o trabalhador resolva efetivar sua filiação deve procurar o sindicato que o representa e solicitar a ficha de inscrição. Muitos sindicatos disponibilizam a ficha através de seus sítios eletrônicos na internet, facilitando o acesso dos trabalhadores à entidade.

Após efetivação de sua filiação, gozará de direitos e deveres perante a entidade, inclusive ter descontado do seu salário, contribuições previstas em assembleias, em convenção coletiva de trabalho e em acordo coletivo de trabalho.

Também terá direito a usufruir de benefícios oferecidos pelo sindicato, tais como assistência médica e odontológica, sede recreativa, consultoria de advogados, descontos em lojas, dentre outros.

A partir de sua filiação, o trabalhador passa a fazer parte da lista de associados do sindicato estando submetido a regras próprias previstas no estatuto da entidade.

\footnotetext{
8 OLIVEIRA NETO, Alberto Emiliano de. O princípio da liberdade sindical e sua plena aplicação ao ordenamento jurídico brasileiro. Disponível em: < $\mathrm{http://}$ www.trt9.jus.br/internet_base/arquivo_download.do?evento=Baixar\&idArquivoAnexadoPlc $=15596$ 59>. Acesso em: 16 abr. 2015.

${ }^{9}$ Tratado de Paz que encerrou oficialmente a primeira guerra mundial, assinado em Versalhes, em 28 de junho de 1919

${ }^{10}$ Declaração adotada pela Organização das Nações Unidas (ONU) em 10 de dezembro de 1948, como uma norma a ser alcançada por todos os povos.
} 


\subsection{OPOSIÇÃO ÀS CONTRIBUIÇÕES}

Muitos sindicatos tem imposto aos trabalhadores de determinadas categorias a obrigatoriedade de expressar oposição às contribuições, especialmente às contribuições assistenciais e confederativas. Não haveria sentido solicitar oposição das demais contribuições, uma vez que a contribuição sindical é um tributo, e por isso, integra o sistema tributário nacional, e a mensalidade sindical, tem anuência expressa do trabalhador, que exerceu seu direito de filiação, e o fez junto à entidade representativa.

Esse direito de oposição fere o princípio da liberdade sindical uma vez que cria obstáculos para o trabalhador exercer seu direito. Seria como ter que manifestar sua opinião cada vez que não concordasse com alguma coisa. São diversas as convenções coletivas que trazem em seu corpo, a obrigatoriedade de o trabalhador ter que expressar sua intenção de não ter descontado do seu salário, valores referentes às contribuições assistencial e confederativa.

Vejamos a $\mathrm{CCT}^{11}$ firmada entre o sindicato da indústria da construção civil do oeste do Paraná e demais entidades representativas dos trabalhadores, cuja vigência abrange o período 2014/2015:

Contribuições Sindicais

CLÁUSULA QUADRAGÉSIMA - CONTRIBUIÇÃO NEGOCIAL

Para assegurar a unicidade jurídica do presente instrumento, retribuir o empenho e trabalho sindical para a realização do mesmo, manter as atividades sindicais e cumprir determinação da Assembleia Geral, as empresas descontarão de seus empregados os seguintes valores, a título de CONTRIBUIÇÃO NEGOCIAL, de conformidade com o artigo 462, 545 e letra e do artigo 513 da CLT. a - Ficam assim estabelecidos os descontos para as entidades convenentes já citadas:

(...)

SINDICATO DOS TRABALHADORES NAS INDÚSTRIAS DA CONSTRUÇÃO E DO MOBILIÁRIO DE MARECHAL CÂNDIDO RONDON; Desconto de 5\% (cinco por cento) sobre a remuneração de cada trabalhador, no mês de Julho de 2014, sendo que deste percentual será repassado $0,5 \%$ (meio por cento) a Federação dos Trabalhadores nas Indústrias da Construção e do Mobiliário do Estado do Paraná, conforme estabelece o Inciso $X$, do artigo $8^{\circ}$ do Estatuto Social. Para o STICM DE MARECHAL CÂNDIDO RONDON, fica assegurado aos empregados não associados/filiados, o direito de oposição à referida contribuição, vedada a oposição promovida ou intermediada pelo empregador ou terceiros, a qual deverá ser apresentada individualmente pelo empregado, diretamente ao Sindicato profissional em sua sede ou sub-sede, ou remessa via postal, no prazo de 30 (trinta) dias a partir da ciência do primeiro desconto realizado no holerite, em requerimento, com identificação e assinatura do trabalhador oponente, salvo em se tratando de empregado analfabeto, quando poderá opor-se através de requerimento, no qual deverá estar atestado por 02 (duas) testemunhas devidamente identificadas. Recebida a oposição, o Sindicato fornecerá recibo de entrega e encaminhará ao empregador, para que não seja procedido o desconto. (grifo nosso) 
(...)

A cláusula acima é um exemplo do que temos visto nas convenções coletivas. A CCT confere ao trabalhador diversas obrigações de forma a dificultar a sua não concordância com o desconto da contribuição.

Apesar de a convenção assegurar ao trabalhador seu direito de oposição, impõe a ele a obrigatoriedade de fazê-lo através de requerimento assinado, e entregue, pessoalmente ou via postal, na sede ou sub-sede do sindicato, num prazo de 30 (trinta) dias a partir da ciência do primeiro desconto. Toda essa formalidade apenas para que o trabalhador informe que NÃO concorda com o desconto em seu salário. Além disso, a CCT coloca um prazo, que se não cumprido, em tese, não permitiria mais ao trabalhador exercer esse -direitoll de oposição.

Ora, o princípio da liberdade sindical descrito na CF-88 não confere aos sindicatos esse poder de limitar a liberdade, o que dirá de impor prazos para sua utilização. Infelizmente essa é uma prática comum dos sindicatos.

Certamente toda essa dificuldade imposta aos trabalhadores tem por objetivo aumentar a base de arrecadação do sindicato, além de não perder a já existente. Ocorre que tal atitude afronta diretamente o direito de liberdade daqueles trabalhadores que não querem participar diretamente do sindicato, optando por não se filiar ao mesmo.

Deve-se respeitar esse direito e para isso o sindicato deveria poupar o trabalhador dessa obrigação impositiva. Se o objetivo do órgão obreiro é aumentar a arrecadação e a base de filiados, deveria convencê-los a abrigar-se no sindicato, mostrando o histórico de lutas e conquistas, além de apresentar todos os benefícios oferecidos.

\section{JURISPRUDÊNCIA}

Há diversos posicionamentos jurisprudenciais a respeito do assunto, inclusive com enunciados e súmulas dos tribunais superiores. O precedente normativo $\mathrm{n}^{\circ} 119$ do Tribunal Superior do Trabalho (TST) é contundente ao afirmar que ofende a liberdade sindical o estabelecimento em ACT e CCT a obrigatoriedade de contribuição dos trabalhadores não sindicalizados.

PN-119 CONTRIBUIÇÕES SINDICAIS - INOBSERVÂNCIA DE PRECEITOS CONSTITUCIONAIS - (nova redação dada pela SDC em sessão de 02.06.1998 - homologação Res. 82/1998, DJ 20.08.1998).

\footnotetext{
${ }^{11}$ CONVENÇÃO Coletiva de Trabalho 2014/2015 dos trabalhadores da indústria da construção civil. Sistema de negociações coletivas de trabalho - MEDIADOR. Registrada em 25/07/2014. Disponível em: <http://www3.mte.gov.br/sistemas/mediador/ConsultarInstColetivo>. Acesso em: 4 set. 2014.
} 
"A Constituição da República, em seus arts. $5^{\circ}, \mathrm{XX}$ e $8^{\circ}, \mathrm{V}$, assegura o direito de livre associação e sindicalização. É ofensiva a essa modalidade de liberdade cláusula constante de acordo, convenção coletiva ou sentença normativa estabelecendo contribuição em favor de entidade sindical atítulo de taxa para custeio do sistema confederativo, assistencial, revigoramento ou fortalecimento sindical e outras da mesma espécie, obrigando trabalhadores não sindicalizados. Sendo nulas as estipulações que inobservem tal restrição, tornam-se passíveis de devolução os valores irregularmente descontados."

(grifo nosso).

Uma vez que a norma coletiva faça a previsão de contribuições assistenciais, confederativas e outras da mesma espécie, para trabalhadores não filiados, essas cláusulas são consideradas nulas e os valores descontados são passíveis de devolução.

A mesma previsão está na OJ-SDC-17 do TST:

\section{OJ-SDC-17 CONTRIBUIÇÕES PARA ENTIDADES}

\section{SINDICAIS. INCONSTITUCIONALIDADE DE SUA EXTENSÃO A NÃO} ASSOCIADOS (inserida em 25.05.1998).

As cláusulas coletivas que estabeleçam contribuição em favor de entidade sindical, a qualquer título, obrigando trabalhadores não sindicalizados, são ofensivas ao direito de livre associação e sindicalização, constitucionalmente assegurado, e, portanto, nulas, sendo passíveis de devolução, por via própria, os respectivos valores eventualmente descontados.

(grifo nosso)

Tanto o PN 119, quanto a OJ-SDC-17, data do ano de 1998, ou seja, há mais de 15 (quinze) anos que o TST entende que é ofensiva ao direito de liberdade sindical a imposição de contribuições aos trabalhadores não filiados aos sindicatos.

Nessa mesma linha de raciocínio, a súmula $n^{\circ} 666$ do STF, publicada em 2003, reforça a exigibilidade de filiação do trabalhador para que possa ser feito o desconto da contribuição confederativa.

Súmula 666

A CONTRIBUIÇÃO CONFEDERATIVA DE QUE TRATA O ART. $8^{\circ}$, IV, DA CONSTITUIÇÃO, SÓ É EXIGÍVEL DOS FILIADOS AO SINDICATO RESPECTIVO.

Recentemente o STF transformou o conteúdo da súmula 666 em súmula vinculante, de modo a dar maior efetividade na sua aplicação, uma vez que vincula todos os tribunais do país. A publicação da súmula vinculante n 40 ocorreu em 20/03/2015:

Súmula Vinculante 40

A contribuição confederativa de que trata o art. $8^{\circ}$, IV, da Constituição Federal, só é exigível dos filiados ao sindicato respectivo.

Com isso temos a máxima corte judicial brasileira anunciando que uma das contribuições sindicais, no caso a contribuição confederativa prevista no artigo $8^{\circ}$ da $\mathrm{CF}$, só 
é devida pelos trabalhadores filiados. Também temos a máxima corte superior do trabalho estendendo esse entendimento também para outras contribuições, como a assistencial e outras de mesma espécie.

Ambas culminam para o entendimento e o respeito do exercício da liberdade sindical do trabalhador. Não poderia ser diferente, pois cabe ao assalariado decidir pela filiação ao seu sindicato representativo.

Com as manifestações dos tribunais superiores, há farta jurisprudência nos tribunais e juízos de $1^{\mathrm{a}}$ instância.

No julgamento do processo $\mathrm{n}^{\circ}$ 0001184-72.2013.5.08.0103, da vara do trabalho do município de Altamira no estado do Pará, proposto pelo Ministério Público do Trabalho, com o fim de se obter liminar para suspender diversas contribuições impostas pelo sindicato local aos trabalhadores não filiados, a juíza do trabalho substituta assim decidiu:

\section{(...)}

Posto isso, defiro o pedido de tutela antecipada no sentido de que o CONSÓRCIO CONSTRUTOR BELO MONTE e as demais empresas requeridas suspendam imediatamente os descontos efetuados nos salários dos atuais trabalhadores a título de contribuição confederativa, assistencial, mensalidade sindical ou quaisquer outras denominações (salvo a contribuição sindical prevista no art. 8o., inciso IV, da CF/88 imposto sindical descontado uma única vez ao ano) e se abstenham de fazê-lo em relação àqueles futuramente contratados, sob pena de multa de $\mathrm{R} \$ 5.000,00$ por infração descumprida, multiplicada pelo número de trabalhadores atingidos, revertida em favor do FAT - Fundo de Amparo ao Trabalhador.

(...)

(grifo nosso)

A decisão beneficiou milhares de trabalhadores que estavam laborando na construção da usina de Belo Monte. Posteriormente o MPT-PA, representado pelo Procurador Allan de Miranda Bruno, propôs acordo ao sindicato obreiro, o que foi aceito. Dentre as cláusulas do acordo destacam-se as seguintes:

\section{I - DAS OBRIGAÇÕES DO SINTRAPAV-PA:}

Cláusula $1^{\mathrm{a}}$. Da cobrança das taxas ou contribuições assistenciais. O sindicato se compromete a observar as seguintes diretrizes quando da cobrança das taxas ou contribuições assistenciais:

1 - Autorização individual do trabalhador para cobrança da contribuição/taxa assistencial, sendo garantido o direito de oposição aos descontos a qualquer tempo, mediante o fornecimento de recibo ao trabalhador pelo exercício de tal direito;

2 - Para os trabalhadores participantes da assembleia geral da categoria, a autorização individual para a cobrança da contribuição/taxa assistencial poderá ocorrer junto com a aprovação da pauta de reivindicações, desde que seja publicada de forma clara aos trabalhadores, que tal contribuição, integra a pauta de reivindicações a ser aprovada pela assembleia geral, sendo garantido o direito de oposição aos descontos a qualquer tempo, mediante o fornecimento de recibo ao trabalhador pelo exercício de tal direito; 


\section{(...)}

É importante destacar a inversão daquilo que vimos nas CCT frente o acordo acima. Ao invés da exigência de manifestação do trabalhador para informar que não quer fazer a contribuição, o acordo prevê a autorização individual do trabalhador para a cobrança. Além disso, o direito de oposição pode ser exercido a qualquer tempo. Nada mais justo e em consonância com o princípio da liberdade sindical, externado no artigo $8^{\circ}$ da carta de 1988 .

No julgamento do recurso de revista interposto no TST, processo $n^{\circ}$ TST-RR112600-32.2009.5.17.0007, a oitava turma do colendo tribunal superior manteve decisão no sentido de restituir valores descontados a título de taxa de fortalecimento sindical.

Vale a pena observarmos a íntegra da decisão em primeiro grau, mantida pelo TRT da $17^{\mathrm{a}}$ região e também pelo TST:

\section{(...)}

4. DA CONTRIBUIÇÃO SINDICAL Requer o reclamante a restituição dos valores descontados a título de contribuição sindical pelo reclamado, uma vez que o mesmo não os autorizou. Alega, inclusive, que sequer era filiado ao sindicato da categoria.

Contrapõe-se o reclamado observando que a convenção coletiva da categoria autoriza o desconto sindical consignado no contracheque do obreiro.

Com razão o reclamante.

Analisando os demonstrativos de pagamento acostados às fls. 108 a 110 , percebe-se que, de fato, eram descontados mensalmente um valor equivalente a $1 \%$ do salário bruto do reclamante sob a rubrica de -taxa de fortalecimento sindical.

A autorização consignada à fl.101, assinada pelo reclamante, refere-se tão somente à possibilidade de desconto da contribuição assistencial. Ademais, a mera previsão em CCT permitindo a retenção de valores a título de taxa de fortalecimento sindical não é suficiente para legitimá-la. Em função do princípio da liberdade associativa, consagrado pela $\mathrm{CF} / 88$, é necessário que o obreiro autorize, expressamente, esse desconto.

Assim, deve o reclamado restituir ao autor os valores descontados sob a rubrica de -taxa de fortalecimento sindicalll no decorrer da relação empregatícia, cujo montante está discriminado à fl. $157(\mathrm{R} \$ 46,16)$.

Pelo exposto, defiro o pedido "C" da exordial. (fl. 225).

(grifo nosso)

Além de manter a sentença em primeiro grau, o tribunal regional suscitou a súmula 342 do TST, que trata da autorização prévia do trabalhador para que a empresa possa efetuar descontos salariais a título de integração em entidade cultural, recreativa e outras.

No Supremo Tribunal Federal foram inúmeras decisões, tanto que resultou na transformação da súmula ${ }^{\circ} 666$ em súmula vinculante. No voto do ministro Dias Toffoli no Agravo Regimental no Recurso Extraordinário $n^{\circ} 495.248$ Sergipe, está citado diversas decisões proferidas pelo STF: 


\section{AG.REG. NO RECURSO EXTRAORDINÁRIO 495.248 SERGIPE}

\section{VOTO}

\section{O SENHOR MINISTRO DIAS TOFFOLI (RELATOR):}

Não merece prosperar a irresignação.

A decisão agravada está em harmonia com a pacífica jurisprudência desta Corte, inclusive sumulada (Súmula $\mathrm{n}^{\circ}$ 666/STF), no sentido de que a contribuição confederativa de que trata o art. $8^{\circ}$, inciso IV, da Constituição Federal é exigível apenas dos filiados ao respectivo sindicato.

Nesse sentido, dentre as inúmeras decisões sobre a matéria, cito as seguintes: AI 437.582/SP-AgR e AI 731.640/SP-AgR, Relator o Ministro Ayres Britto, Primeira Turma, ambas publicadas no DJe de 28/08/09; AI 476.877/RJAgR, Relatora a Ministra Ellen Gracie, Segunda Turma, DJ de 03/05/06; AI 612.502/RS-AgR, Relator o Ministro Eros Grau, Segunda Turma, DJ de 23/02/07; AI 706.379/SP-AgR, Relatora a Ministra Cármen Lúcia, Primeira Turma, DJe de 19/06/09; e RE 176.533/SP-AgR, Relator o Ministro Cezar Peluso, Segunda Turma, DJe de 16/05/08, essa última assim ementada:

"Extraordinário. Inadmissibilidade. Jurisprudência assentada. Contribuição confederativa. Exigibilidade apenas de filiados. Aplicação da súmula 666. Ausência de razões novas. Decisão mantida. Agravo regimental improvido. Nega-se provimento a agravo regimental tendente a impugnar, sem razões novas, decisão fundada em jurisprudência assente na Corte".

Ademais, ressalto o seguinte trecho do julgado acima citado, proferido pelo Ministro Cezar Peluso:

"É oportuno, aliás, advertir que o disposto no art. 544, §§ $3^{\circ}$ e $4^{\circ}$, e no art. 557, ambos do Código de Processo Civil, desvela o grau da autoridade que o ordenamento jurídico atribui, em nome da segurança jurídica, às súmulas e, posto que não sumulada, à jurisprudência dominante, sobretudo desta Corte, as quais não podem desrespeitadas nem controvertidas sem graves razões jurídicas capazes de lhes autorizar revisão ou reconsideração. De modo que o inconformismo sistemático, manifestado em recursos carentes de fundamentos novos, pode caracterizar abuso do poder recursal".

Nego provimento ao agravo regimental.

Apesar de a maioria dos sindicatos convencionarem em suas normas coletivas que as contribuições devem ser descontadas de todos os trabalhadores, independentemente de filiação, a jurisprudência é majoritária na defesa da liberdade sindical dos trabalhadores. Além de majoritária, toma formas mais concretas no sentido de fortalecer esse entendimento, conforme vimos na novíssima súmula vinculante $n^{\circ} 40$ do STF.

\section{POSICIONAMENTO DO ÓRGÃO FISCALIZADOR}

O Ministério do Trabalho e Emprego é o órgão fiscalizador das relações de trabalho, inclusive de normas de saúde e segurança relacionadas ao trabalho. Também é o MTE quem fiscaliza os recolhimentos das contribuições sindicais, sobretudo, daquelas previstas em acordos e convenções coletivas. A fiscalização é exercida pelos Auditores- Fiscais do 
Trabalho, através da Secretaria de Inspeção do Trabalho (SIT), conforme previsão da Lei $\mathrm{n}^{\circ} 10.593$ de 6 de dezembro de 2002.

Art. 11. Os ocupantes do cargo de Auditor-Fiscal do Trabalho têm por atribuições assegurar, em todo o território nacional:

(...)

IV - o cumprimento de acordos, convenções e contratos coletivos de trabalho celebrados entre empregados e empregadores;

(...)

(grifo nosso)

Uma vez que o ACT e CCT faz lei entre as partes, cabe à fiscalização do trabalho verificar o cumprimento das cláusulas previstas. Se há previsão de recolhimento de contribuições sindicais dos empregados, é dever do empregador fazê-lo. Ressalte-se que a contribuição sindical prevista no art. $8^{\circ}$ da CF, independe de previsão em ACT e CCT, uma vez que se trata de um tributo federal.

A dúvida que surge, frente às contribuições previstas nas normas coletivas, é quanto ao recolhimento dos trabalhadores não filiados aos sindicatos. O que acontece é que há a previsão do recolhimento nos ACT e CCT mesmo para os trabalhadores não filiados, o que contraria a liberdade sindical desses trabalhadores.

Com isso, a fiscalização passou a ter vários entendimentos por parte dos AuditoresFiscais do Trabalho, o que acabou gerando procedimentos distintos durante as auditorias. O próprio órgão fiscalizador se deparou com esse questionamento e viu-se obrigado a manifestar-se a respeito em diversas ocasiões.

No ano de 2004 houve uma tentativa por meio da Portaria $\mathrm{n}^{\circ}$ 160, de 13 de abril de 2004. A norma dispunha sobre o desconto em folha das contribuições instituídas pelos sindicatos. Já no primeiro artigo, a norma explicita a necessidade de filiação para o desconto da contribuição.

Art. $1^{\circ}$ As contribuições instituídas pelos sindicatos em assembleia geral da categoria, em especial a confederativa e/ou as constantes de convenção ou acordo coletivo e sentença normativa, em especial a contribuição assistencial, são obrigatórias apenas para os empregados sindicalizados. (grifo nosso)

Ocorre que, por vício constitucional, a portaria foi considerada inconstitucional pelo STF (ADIN 3206-2 e 3353-1).

Posteriormente, a consultoria jurídica do Ministério do Trabalho, emitiu o Parecer $\mathrm{n}^{\circ}$ 579/2008 em virtude da solicitação de entidades sindicais do estado de Santa Catarina a respeito da legalidade de atuação de Auditores-Fiscais do Trabalho.

\section{(...)}

20. Nesse diapasão, dúvida não há quanto à impossibilidade da incidência compulsória das contribuições instituídas em Assembleia Geral ou em 
instrumento coletivo sobre aqueles trabalhadores não filiados ao ente sindical. Ratifica-se, assim, o posicionamento esposado por esta CONJUR/MTE em manifestações anteriores.

(...)

(grifo nosso)

Percebemos que, o órgão fiscalizador também manteve o entendimento da impossibilidade de recolhimento das contribuições assistenciais e confederativas dos obreiros. Apesar desse posicionamento, aparentemente solidificado, em 2009, o ministro do trabalho, Carlos Lupi, emitiu a Ordem de Serviço n ${ }^{\circ}$, de 24 de março de 2009.

Ao invés de clarear, a ordem de serviço deixou mais nebulosa o assunto, de modo que impôs ao trabalhador a necessidade de oposição do empregado não sindicalizado. Além disso, apresentou prazo de 10 (dez) dias após ser informado pelo sindicato da cobrança.

Sem saber como agir, agentes de fiscalização pediram informações à Secretaria de Inspeção do Trabalho, que respondeu através da Nota Técnica $n^{\circ}$ 109/2009/DMSC/SIT. A nota técnica se fundamenta em três pontos principais. Primeiro no sentido de interpretar a ordem de serviço sem afastar a lei, ou seja, uma norma administrativa não pode prever algo diferente da lei.

O segundo ponto é a aplicação do art. 545 da CLT:

\begin{abstract}
Art. 545 - Os empregadores ficam obrigados a descontar na folha de pagamento dos seus empregados, desde que por eles devidamente autorizados, as contribuições devidas ao Sindicato, quando por este notificados, salvo quanto à contribuição sindical, cujo desconto independe dessas formalidades. (Redação dada pelo Decreto-lei $n^{\circ}$ 925, de 10.10.1969) (grifo nosso)
\end{abstract}

Baseado no artigo acima a NT prevê que "Tal autorização, como delimita o próprio dispositivo, constitui requisito formal (solene), razão pela qual entendemos que deva ser feita necessariamente por escrito." 12 .

Por último, a nota técnica destacou que o custeio das atividades sindicais é feito por todos os trabalhadores, filiados ou não aos sindicatos, através do imposto sindical.

Nesse contexto, temos que o órgão que fiscaliza o cumprimento das relações de trabalho, inclusive acordos e convenções coletivas, caminha na mesma via do poder judiciário no entendimento de que contribuições assistenciais e confederativas sejam descontadas apenas dos trabalhadores filiados.

O trabalhador, no exercício do seu direito de liberdade de escolha, que opta pela filiação, terá descontado do seu salário, mediante sua concordância formal, os valores previstos em normas coletivas a título de contribuições assistenciais e confederativas. Também arcará com o pagamento da mensalidade sindical, se previsto no estatuto da entidade sindical. 


\section{CONCLUSÃO}

A importância dos sindicatos na estrutura de trabalho existente é indiscutível. Também não se discute a necessidade de fortalecimento desses sindicatos para que sejam fortes e atuantes, de modo a dar efetividade na sua ação.

Para isso é necessário um financiamento apropriado e suficiente para o desenvolvimento de suas atividades. O imposto sindical previsto no artigo $8^{\circ}$ da $\mathrm{CF}$ é a principal forma de arrecadação dos sindicatos e tem por objetivo atender suas principais necessidades. É um imposto que atende uma coletividade de pessoas, independentemente de filiação, sobrepondo a individualidade do trabalhador.

Para as demais contribuições é necessário que o princípio da liberdade sindical seja atendido, de modo que, apenas os trabalhadores que queiram participar façam a sua contribuição. A intenção de diversos sindicatos de impor todas as contribuições para empregados não filiados, afronta de forma direta à liberdade de cada um.

A constituição federal cumpriu seu papel ao prever uma forma de custeio coletivo dos sindicatos. Se quisesse estender esse custeio com outras contribuições teria feito. Ao invés disso, enfatizou a liberdade de filiação e delegou à lei outras formas de custeio, de modo a não frear o crescimento sindical e propiciar o seu fortalecimento.

O trabalhador não pode se furtar de contribuir para o funcionamento sindical, uma vez que também é beneficiado com sua atuação, seja através de serviços prestados pelo sindicato, seja através dos acordos e convenções coletivas de trabalho. Por outro lado, o trabalhador tem o direito de decidir se amplia essa participação através de sua filiação. Sindicatos fortes que oferecem um leque grande de benefícios geralmente têm uma base de trabalhadores filiados bastante grande.

Se os trabalhadores, filiados ou não, fossem obrigados a contribuir com todas as contribuições, nem estaríamos falando em liberdade sindical. Também não faria diferença a formalização da filiação. Todos seriam filiados automaticamente uma vez que teriam que contribuir de forma compulsória. Se o objetivo fosse esse, a constituição não traria a liberdade sindical de forma expressa. Essa liberdade prevista no artigo $8^{\circ}$ se coaduna com os direitos trabalhistas previstos nos artigos $5^{\circ}$ e $7^{\circ}$, que dá à carta a característica de constituição cidadã.

É preciso que constituição seja respeitada uma vez que é a representação da vontade popular. Normas inferiores devem sempre respeitar a constituição e ser usada para por em prática os princípios destacados na carta magna.

\footnotetext{
${ }^{12}$ BRASIL. Secretaria de Inspeção do Trabalho. Nota Técnica $\mathbf{n}^{\circ}$ 109/2009/DMSC/SIT. Arquivo pessoal. p. 5.
} 
As normas coletivas criadas por entidades sindicais devem total obediência à legislação em vigor e não podem extrapolar suas competências.

Uma vez que isso é feito, corre-se o risco de criar uma jurisprudência inferior de modo a enfraquecer direitos individuais dos trabalhadores, sobre tudo liberdades conquistadas ao longo da história nacional. A defesa das liberdades deve ser exercida por todos, sobretudo pelas entidades que representam os trabalhadores.

\section{REFERÊNCIAS}

BASSO, Maristela e POLIDO, Fabrício. A Convenção 87 da OIT sobre Liberdade Sindical de 1948 - recomendações para a adequação do direito interno brasileiro aos princípios e regras internacionais do trabalho. Disponível em < http://www.tst.jus.br/web/biblioteca/2012-vol.-78>. Acesso em: 4 abr. 2015.

BRASIL. Constituição da República Federativa do Brasil de 1988. Disponível em: < http://www.planalto.gov.br/ccivil_03/constituicao/constituicaocompilado.htm>. Acesso em: 21 jan. 2015.

. Decreto Lei $\mathrm{n}^{\mathrm{o}}$ 1.402, de 5 de julho de 1939. Disponível em: < https://http://www.planalto.gov.br/ccivil_03/decreto-lei/del1402.htm>. Acesso em: 16 mar. 2015.

Decreto Lei $n^{\mathbf{0}}$ 4.552, de 27 de dezembro de 2002. Disponível em: < http://https://www.planalto.gov.br/ccivil_03/decreto/2002/d4552.htm>. Acesso em: 9 abr. 2015 .

http://www.planalto.gov.br/ccivil_03/decreto-lei/del5452.htm>. Acesso em: 21 jan. 2015.

Lei $n^{0}$ 10.593, de 6 de dezembro de 2002. Disponível em: < http://http://www.planalto.gov.br/ccivil_03/LEIS/2002/L10593.htm>. Acesso em: 9 abr. 2015.

. Lei no 11.648, de 31 de março de 2008. Disponível em: < http://www.planalto.gov.br/ccivil_03/_Ato2007-2010/2008/Lei/L11648.htm>. Acesso em: 9 abr. 2015.

CARRION, Valentin, 1931-2000. Comentários à consolidação das leis do trabalho. 35. ed. atual. por Eduardo Carrion. São Paulo: Saraiva, 2010.

CAMINO, Carmen . Direito individual do trabalho. 4. ed. Porto Alegre: Síntese, 2004. 
CONVENÇÃO Coletiva de Trabalho 2014/2015 dos professores das instituições privadas de ensino superior de Cascavel. Sistema de negociações coletivas de trabalho - MEDIADOR. Registrada em 31/03/2014. Disponível em: <http://www3.mte.gov.br/sistemas/mediador/ConsultarInstColetivo>. Acesso em: 5 set. 2014.

CONVENÇÃO Coletiva de Trabalho 2014/2015 dos trabalhadores da indústria da construção civil. Sistema de negociações coletivas de trabalho - MEDIADOR. Registrada em 25/07/2014. Disponível em: <http://www3.mte.gov.br/sistemas/mediador/ConsultarInstColetivo>. Acesso em: 4 set. 2014.

COSTA, Armando Casimiro; FERRARI, Irany; MARTINS, Melchíades Rodrigues. Consolidação das Leis do Trabalho. 39 ed. - São Paulo: Ltr, 2012.

DELGADO, Maurício Godinho. Curso de direito do trabalho. 9. ed. São Paulo: LTr, 2010 .

FIORAVANTE, Tamira Maira e AlOUCHE, Luiz Fernando. Fontes de custeio dos sindicatos no Brasil. Disponível em: http://www.migalhas.com.br/dePeso/16,MI139029,91041-

Fontes+de+custeio+dos+sindicatos+no+Brasil>. Acesso em: 19 set. 2014.

JOÃO, Paulo Sérgio; MANUS, Pedro Paulo. Temas em direito do trabalho: direito material individual. São Paulo: LTr, 2008.

LOURENÇO FILHO, Ricardo Machado. Liberdade sindical: percursos e desafios na história constitucional brasileira. São Paulo: LTr, 2011.

MARTINS, Sérgio Pinto. Convenções da OIT. São Paulo: Atlas, 2009. MARTINS, Sérgio Pinto. Direito do Trabalho. 24. ed. São Paulo: Atlas, 2008.

MELO, Cláudia Virgínia Brito de. Contribuição sindical. Consultoria legislativa. Câmara dos deputados. Brasília: 2005.

NASCIMENTO, Amauri Mascaro. Compêndio de direito sindical. 6. ed. São Paulo: LTr, 2011.

NASCIMENTO, Amauri Mascaro. Curso de direito do trabalho: história e teoria geral do direito do trabalho: relações individuais e coletivas do trabalho. 23. ed. São Paulo: Saraiva, 2008.

OLIVEIRA NETO, Alberto Emiliano de. O princípio da liberdade sindical e sua plena aplicação ao ordenamento jurídico brasileiro. Disponível em: < http:// 
www.trt9.jus.br/internet_base/arquivo_download.do?evento=Baixar\&idArquivoAnexado Plc=1559659>. Acesso em: 16 abr. 2015.

PANTALEÃO, Sérgio Ferreira. Contribuição sindical / confederativa / assistencial. O que deve ou não ser descontado?. Disponível em < http://www.guiatrabalhista.com.br/tematicas/contribuicoessindicais.htm>. Acesso em: 23 ago. 2014.

PAULO, Vicente; ALEXANDRINO, Marcelo. Manual de direito do trabalho. 13. ed. rev. e atual. Rio de Janeiro: Forense; São Paulo: MÉTODO, 2009.

PEREIRA, Ricardo José Macedo de Brito. Constituição e liberdade sindical. São Paulo: LTr, 2007

SANTOS, Jonabio Barbosa dos. Liberdade sindical e negociação coletiva como direitos fundamentais do trabalhador. São Paulo: LTr, 2008.

SANTOS, Luiz Alberto Matos dos. A liberdade sindical como direito fundamental. São Paulo: LTr, 2009.

SILVA, Francisco José Gomes. Fundamentos constitucionais e normativos da organização sindical do magistério superior no Brasil: Andes - SN. 2010. 90 f. Dissertação de mestrado - Fundação Edson Queiroz, Universidade de Fortaleza, Fortaleza.

SARAIVA, Renato (Org.); MANFREDINI, Aryanna (Org.); SOUTO, Rafael Tonassi (Org.). CLT - Consolidação das leis do trabalho. 13. ed. Rio de Janeiro: Forense; São Paulo: MÉTODO, 2015.

VIANNA, Cláudia Salles Vilela. Manual prático das relações trabalhistas. 12. ed. São Paulo: LTr, 2014.

VIEGAS, Weverson. Liberdade sindical. Disponível em: <http://jus.com.br/artigos/4063/liberdade-sindical>. Acesso em: 10 mar. 2015. 